\title{
Changes in the provision of health care in South Africa
}

\author{
J. Luiz \\ Wits Business School, University of the Witwatersrand \\ Johannesburg, Republic of South Africa \\ luiz.j@wbs.ac.za \\ M. Wessels* \\ PO Box 3673, Cresta 2118, Republic of South Africa \\ martinwes@icon.co.za \\ November 2003
}

\begin{abstract}
Health care in South Africa is undergoing substantial changes with rising pressure on both the public and private sectors. Medical inflation has been soaring rendering healthcare increasingly unaffordable and medical schemes have had to adapt their traditional business models. This paper looks at the current structure of the healthcare market; it examines the new legislation introduced by government, and assesses future directions of healthcare in South Africa.
\end{abstract}

*To whom all correspondence should be addressed.

\section{Introduction}

Creating good healthcare services to serve an entire nation takes time and resources. Unfortunately these obstacles prevent the South African government from instantly redressing the imbalances of the past. This paper examines the steps the current government has taken, and intends to take, to improve the quality of healthcare and service a larger proportion of the population.

The South African government is faced with four challenging problems in the healthcare market:

1. The public sector does not have the resources to provide adequate healthcare to the large population not covered by private medical cover.

2. The number of people covered by medical aids has been stagnant and as a percentage of the population is actually declining.

3. The increasing costs of private healthcare have continually outstripped inflation and have now reached a point where private healthcare has been unable to grow due its high cost.

4. How can the public and private sector be better moulded to improve the quantity and quality of healthcare received by a larger number of the population?

Before we can look at how government has been and intends to deal with these challenges, we need to understand the structure of and challenges faced by the South African healthcare market.

\section{Overview of the South African healthcare sector}

The total expenditure on health in South Africa as a percentage of GDP is $8,8 \%$, which is high by the international standards (UNDP, 2001). South Africa spends $\$ 623$ per capita per annum on health, which is the highest of all medium human development countries (UNDP, 2001:159). However, only $34 \%$ of total health expenditure is public whilst private expenditure makes up the other $66 \%$. Havemann and Van den Berg (2003:22) found that private healthcare plays a very important role in South African healthcare. They maintain that the often-quoted maxim that the private sector only serves 7 million people is highly unlikely. Their study shows that a larger than expected number of poor people make use of private healthcare and indeed have strong preferences for private healthcare. In addition they argue that as incomes increase greater demands will be put on the private healthcare market because public primary health care has inferior good characteristics.

The public and private sector healthcare markets are facing a diverse range of challenges which are outlined below.

\section{The public sector}

South Africa has undergone significant social and political changes over the last decade and this has impacted the government's view of the healthcare market. The vision of the Department of Health is that all South Africans should have access to affordable, good quality healthcare. Traditionally the state has been responsible for providing healthcare to the poor who have conventionally been excluded from the private medical aid system mainly for socio-economic reasons. 
The public sector has been plagued with a lack of resources, which has led to poor quality healthcare provision in many areas. The private sector has not been able to participate in the provision of public health on behalf of the state because the state has a closed ordering system that is not suitable for interaction with the private sector. The result is that the public sector is taking enormous strain as more and more people make use of its inadequate services. The impact of HIV/AIDS has put further strain on the system.

Apartheid policies resulted in public healthcare being very skewed in distribution, with the majority of services being placed in the urban areas. With only half of the population living in urban areas the government is faced with the difficult task of providing health care to the rural masses where poverty is more widespread. What exacerbates this problem is that a much larger percentage of people in rural areas are not on medical aids and thus far more reliant on the government to provide health services.

In an attempt to provide better access to people in the rural areas there has been a move to focus on primary healthcare (PHC) rather than hospital based health care as most of the larger hospitals are situated in urban areas. PHC has been a policy that many developing countries have followed but not always with the desired results. Whilst in theory it seems to be a basis to provide ideal health care solutions for the masses, it has numerous problems with regard to its implementation. A common problem with PHC systems is the difficulty of filling posts in rural areas. One of the reasons is that medical staff are highly educated and prefer the urban life where they benefit from increasing returns to human capital interaction. A recent study of Indonesian medical graduates found that the amount of pay required to induce relocation to remote rural areas was multiples of the current wage rate (cited in Filmer et al., 2002:60). To overcome this obstacle, the South African government has started forcing newly graduated health professionals to do one year's community service in an attempt to fill these posts. However, according to the Rural Doctors Association of South Africa, compulsory community service has failed to alleviate the crisis in staffing in rural hospitals. Of the 1,173 applications for community service posts in 2001, $83 \%$ of doctors were placed in urban hospitals (SAIRR, 2001:313). The Department of Health is trying to address the imbalance between medical practitioners in urban and rural areas by implementing a certificate of need. Should the Act be signed into law, doctors will have to apply for a certificate of need to be able to practice in a specific area. Whether the certificate will be issued will be determined by the number of medical practitioners in the area and whether there is a need for the medical practitioner in that locality. This system is seen as way to force doctors into more rural areas where there is a greater need. The medical practitioners are violently opposed to such legislation, as they believe it is unconstitutional to prevent someone working in the place of their choosing. They also say that it would not be economically viable to open medical practices in poor rural areas. Unfortunately coercive legislation like this could have unintended consequences which could exacerbate the problem e.g. encouraging emigration of medical practitioners. A better system would be to subsidize doctors who are willing to work in designated rural areas and thus entice them to move to these areas.

Another reason that the state is struggling to fill posts is that the remuneration is far below that of the private sector. This is illustrated by a statement in April 2001 by the Minister of Health who stated that 337 of the 475 unfilled pharmacists' posts in state hospitals and clinics had been vacant for over a year (SAIRR, 2001:312). This has led to poor working conditions and overworked health professionals as a result of manpower shortages. Likewise, some $35 \%$ of doctors in South Africa cater for the 35 million people who use the public sector healthcare facilities; whilst $65 \%$ of doctors are in private practice and cater for the 7 million people who belong to medical aid schemes, which indicates just how much more lucrative the private sector is (SAIRR, 2001:312).

\section{The private sector}

The South African private sector accounted for $66 \%$ of the total health care spend in South Africa in 2000. Of the total private health care bill of R58,8 billion, R35,5 billion was spent by medical aids whilst the remaining R17,3 billion represents out-of-pocket expenditure (Havemann \& Van der Berg, 2003: 22). In 2001 the medical aid membership stood at just under 7 million. Thus, in the private sector the medical aids have tremendous power in terms of the allocation of spending. However, they also realize that there are approximately 33 million people that are not covered by medical aids (SAIRR, 2001:301). This leaves a tremendous window of opportunity for medical aids to expand if they are willing and able to create an affordable product for this large untapped market. This is verified by a labour survey in 2001 that showed that in the main business industries in South Africa only $29 \%$ of employees contribute to a medical aid (SAIRR, 2001:300).

The standard of medicine practiced by the private healthcare market in South Africa is comparable with the best in industrialised countries. This can be seen by the significant health breakthroughs achieved in South Africa (e.g. the first heart transplant) and the fact that South African health specialists are respected worldwide as is illustrated by the rising recruitment of our medical professionals abroad. The private healthcare market in South Africa offers leading medical procedures, which are sometimes very expensive and this may partly account for why private healthcare costs have been growing well above inflation which mirrors the international experience. Whilst this can be seen as a strength in terms of the quality of healthcare in South Africa, it can also be seen as a weakness as it excludes a vast majority of the population from affordable private healthcare.

The private sector has traditionally consisted of consumers contracting to medical aids, which then pay providers of medicine on a fee for service basis. Unfortunately such a system is open to abuse in terms of fraud and over-supply of services. With the incentive to oversupply and the rapid increase in costly technology available to treat diseases, the rate of increase of medical inflation has been much higher than the general rate of inflation. The high inflationary 
increase in the price of medicine is compounded by a lack of a cost conscious consumer. This classic moral hazard problem arises because the insurer pays the medical costs and thus the consumer does not take on the medical costs directly. The consumer does thus not put pressure on price containment and competition, as would be the case in other industries where the consumer pays directly (Rietveld, 1996:12). The threat of such moral hazard can be addressed by medical aids by implementing various policies such as the introduction of co-payments, which immediately make consumers more price conscious.

The rapid rise in medical inflation have put enormous pressure on medical aids to contain costs and to keep their premiums affordable. This has also been compounded by the fact that the more affluent people who can afford medical aids are living longer thus adding to the price constraints that medical aids face. It is argued that with the rapid rise of premiums the younger, healthier members that traditionally subsidized the older, generally more sickly members are selecting not to join traditional medical aids leading to an adverse selection problem. They are choosing alternatives like savings plan schemes or hospital plans which only cover major medical emergencies. This has increased the risk to the medical aids as the older members are no longer being subsidized by younger members who are not joining traditional medical aids in the numbers required to sustain the current system. At the same time older members who subsidized the previous generation when they where young and healthy, now feel a sense of entitlement to receive the same subsidization. Added to this is the growth in wealth in the new black middle class where there is a reluctance to subsidize an ageing white population. The opportunity exists for some medical aids to exploit the situation by actively marketing its medical aid to younger, healthier members to the exclusion of older high-risk members. This practice is termed cream skimming.

With the pressure that medical aids are facing, they have been forced to look at new ways to contain costs such as pushing for managed health care. This can be defined as a system that manages the utilization, costs (including the inflation rate) and quality of services to ensure that a defined population receives appropriate, cost effective and high quality healthcare (Chetty, 2000: 1). The basis of managed healthcare is that it begins with cost cutting measures such as demanding discounts and proceeds to its most advanced form with a transfer of risk from the medical aid to the health provider, and thus the provider becomes motivated to reduce costs. Managed healthcare began with providers opting into agreements with medical aids to provide services at bigger discounts and is now moving away from fee for service towards capitation systems. A capitation system is where the provider is given a fixed fee per month to maintain the health of an individual, with part of the risk being carried by the provider. This system disincentives the provider from over-supplying but care must be taken that providers do not under-supply as service levels could drop and lead to customer dissatisfaction. This is also a good way of overcoming moral hazard in the healthcare market. The difficulty is in reaching an equitable solution where costs are contained at acceptable levels and at the same time the patient receives an acceptable level of service.

Medical aids have thus far failed to keep costs contained at acceptable levels. This has lead to premium increases which have far outstripped the inflation rate. The effect of this is that there has been a steady decline in the coverage of the population by medical schemes, which is illustrated in the following figure.

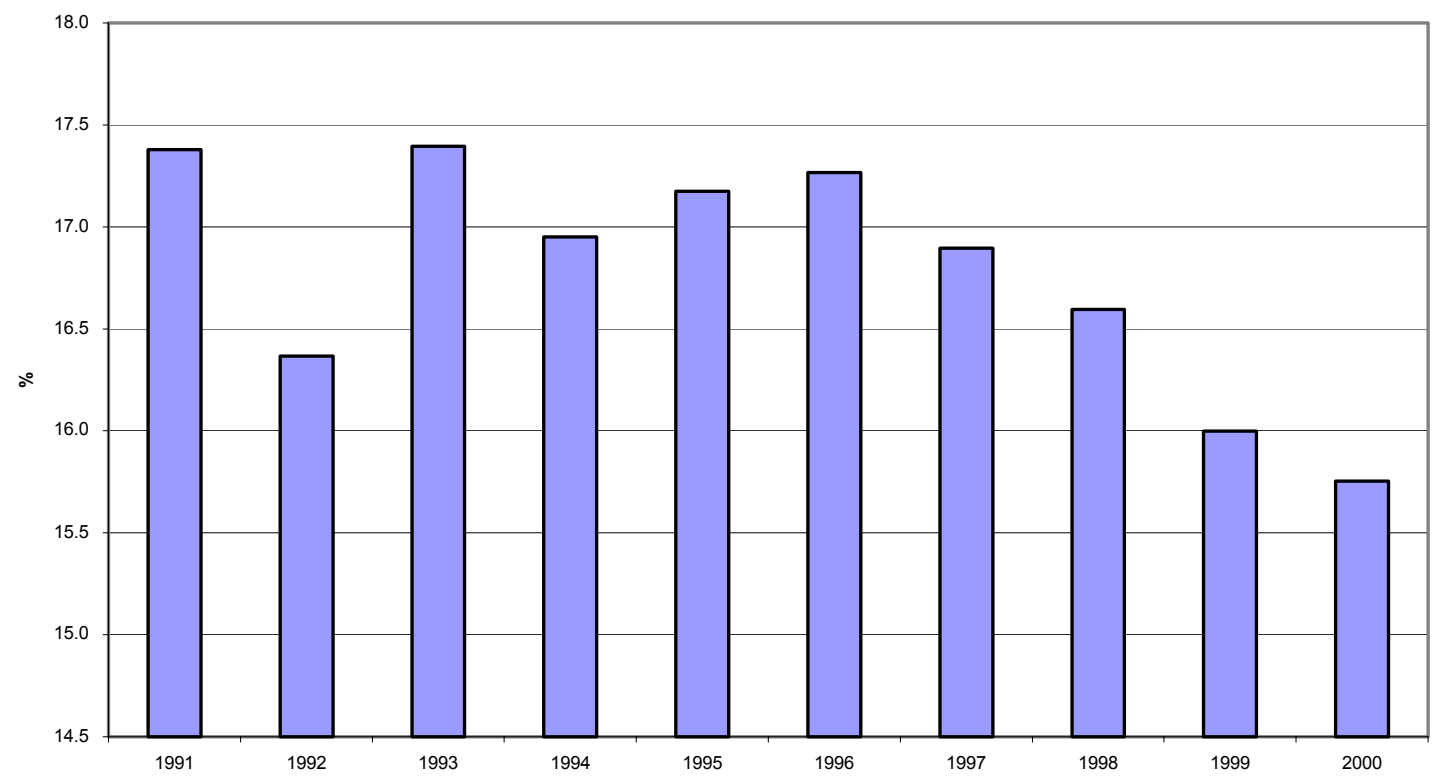

Figure 1: Medical scheme coverage 1991-2000

Source: Council for Medical Schemes, 2002. 
This decline can be attributed to the increasingly high costs of medical aids in South Africa and the fact that many of the large employers in South Africa, which traditionally provided their employees with medical aids, are reducing there workforces, whilst small companies cannot afford to provide medical benefits. Related to this is the fact that South Africa is not creating jobs in the formal market and thus more and more people are unemployed and excluded.

\section{The South African medical aid industry}

The South African medical aid industry has been going through difficult times over the last few years. Medical aid scheme membership has stagnated at around 7 million and the patient pool is ageing. The government has recently introduced the Medical Aid Amendment Act with the aim of widening private sector membership by outlawing discrimination on any basis other than family size and income. By removing medical aids' capacity to selectively choose low risk members, medical aids are now being forced to compete by negotiating better deals with hospitals, doctors and service providers.

Medical costs have increased dramatically in recent years and now consume $10 \%$ of the average company's payroll. This has forced employers to scale back on medical benefits and to pass more of the burden onto employees. These increases in medical costs have forced $10-20 \%$ of employers to buy down to cheaper scheme options each year. Brian Brink, the chairman of the Board of Healthcare Funders (BHF), says 'Private healthcare is, if not already in crisis, moving towards crisis rapidly and something has to be done' (Financial Mail, 27/7/2002:50). There is thus great concern as to how the current system of pay for service can be adapted to some new form of private healthcare, which will be viable for all involved parties. Such changes might include risk-sharing arrangements with providers to bring down costs in a sustainable way. Unfortunately few healthcare providers are geared for these changes. The problem is exacerbated by the fact that change is always difficult when an industry is very well established. Since it is not yet clear exactly what form the private industry will move towards, established players are very reluctant to change and risk the status quo.

Medicines represent roughly $30 \%$ of medical aid annual benefit expenses. Most of these medicines or at least the active ingredients are imported from abroad. With the decline in the value of the Rand over the past few years, the prices of medicines have increased substantially. This has put pressure on medical aids as they are often forced to pass these costs on to their customers. The growth in the cost of healthcare can be seen in the trends in benefits paid by medical schemes illustrated below.

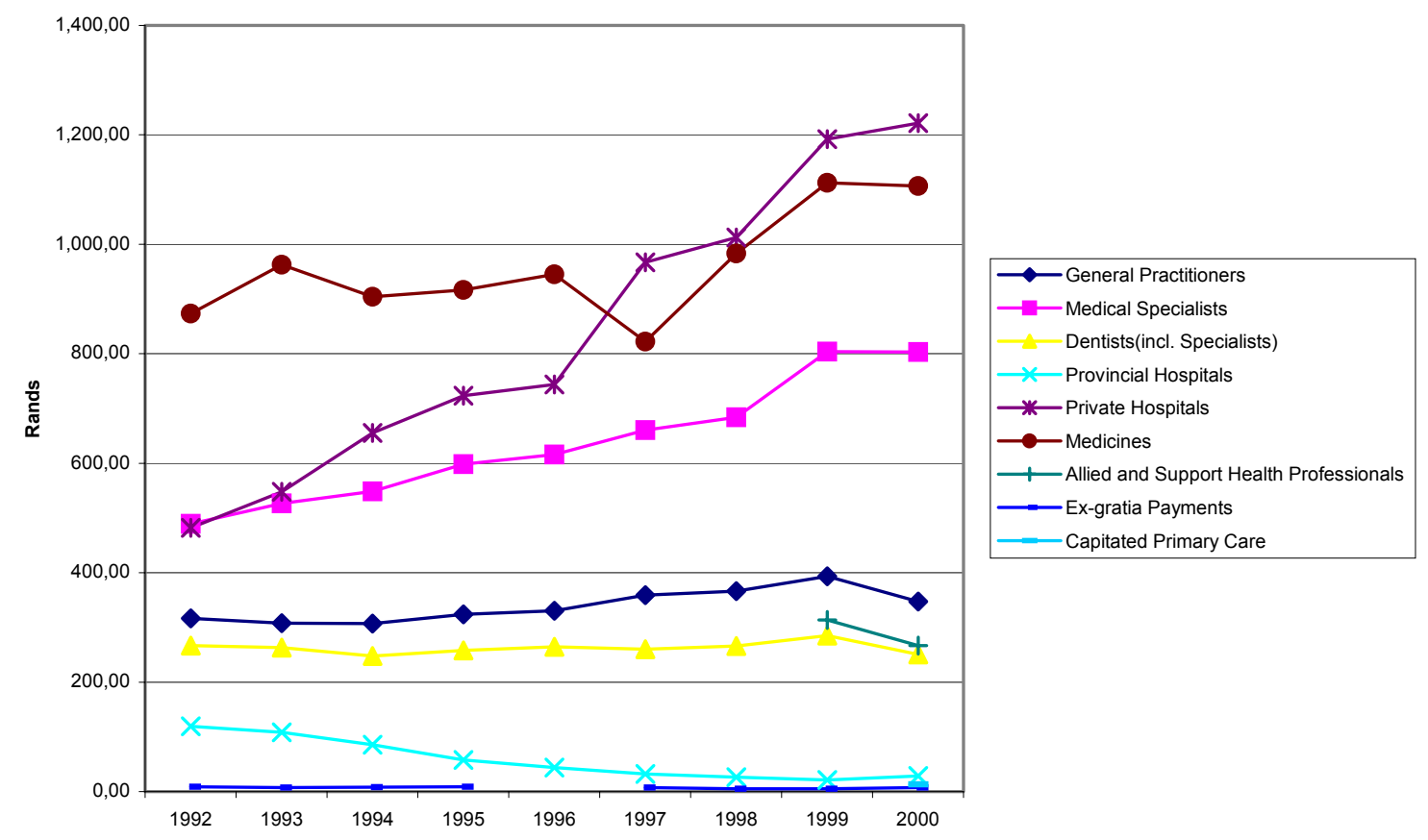

Figure 2: Real cost per beneficiary (constant 2001 prices)

Source: Council for Medical Schemes (www medicalschemes.com). 
Medicines account for roughly $30 \%$ of the total healthcare bill, which is high compared to many other countries. For example, in Ireland and the Netherlands it accounts for 7,7\% of health expenditure, in the UK and Denmark $11,1 \%$, and in France, Italy, and Belgium it is roughly 17\% (Reekie, 1995: 90). Reasons that have been suggested for this in South Africa include:

- Most manufacturers tender to the public sector at very low prices and then charge the private sector higher prices to ensure overall desired profitability.

- The fact that ownership of pharmacies has in the past not been open to non-pharmacists and thus competition has been stifled and larger more efficient organisations have not been allowed to compete with their better distribution systems.
- South African has been slow in the growth of generic substitution.

Private hospitals continue to receive the bulk of the benefits paid to service providers by medical schemes followed by medicines and medical specialists whilst general practitioners and dentists experienced a drop in the amount of benefits paid to them. In contrast the bulk of the benefits paid out from medical savings account went to medicines followed by medical specialists.

In the past few years, medical inflation has consistently been much higher than the consumer price index which has meant ever rising medical aid premiums. The medical aids have now reached a point where they run the risk of pricing themselves out of the market. See the figure below.

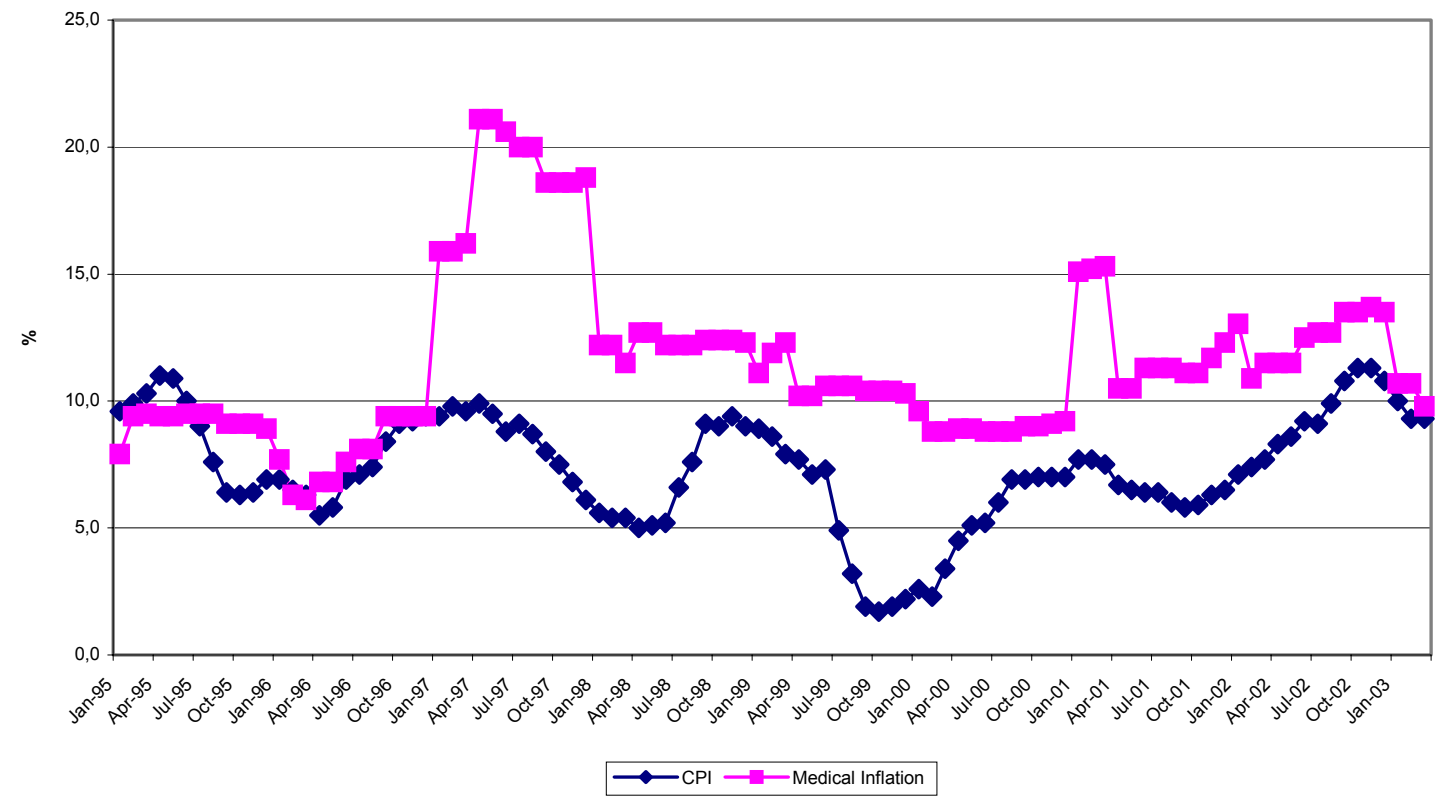

Figure 3: Consumer price index versus medical inflation

Source: Council for Medical Schemes (www medicalschemes.com).

Given that medical aids are constrained in increasing their premiums they are being forced to find new ways of containing costs. How they will achieve their cost savings will be of critical importance to medical professionals, as they will be directly impacted by these changes.

\section{The structure of the medical aid industry}

Traditionally South African medical aids have operated on a fee for service basis. This means that the healthcare provider supplies a service and then bills the medical aid. Thus it is in the healthcare provider's best interest to provide as much service as possible to maximize returns. This has led to providers supplying the most expensive treatment to the patient who is indifferent to cost, leaving the medical aid to foot the bill. The healthcare providers have felt the pressure to constantly upgrade to the latest technology with which to attract customers who demand the best medical service irrespective of cost. Another reason for increasing costs is the shifting demographics as the medical aid population ages and lives longer requiring more treatment. Medical aids have met these rising costs by constantly increasing membership contributions.

A point has now been reached where employers and consumers can no longer afford increasing contributions and are looking at more affordable options. Consumers are beginning to see the severity of the situation and are actually taking an interest in reducing costs so as to assist medical aids in keeping their premiums down. This change in sentiment has opened a window of opportunity for medical aids and allowed them to impose widespread changes in the structure and administration of healthcare in the private sector without fierce opposition from members. Consumers are now prepared to sacrifice convenience if this means reduced medical costs. These changes are going to have major repercussions on the conditions under which medical services are provided in the future. 
Of interest is that even with medical aids complaining that medical inflation is forcing up their contributions, recent medical aid contributions increases are running ahead of medical claims suggesting that medical aids are making better profits than they are letting on. See the figure below.

Shaun Mattison of Discovery Health (one of South Africa's largest medical aid schemes) believes that the new Act is failing in meeting its objective of broadening access to the healthcare market. He says that 'It's very difficult to put capital at risk in not-for-profit medical schemes. The Act needs greater flexibility to attract the young and healthy' (Ryan, 2002: 6). This is illustrated by the fact that the increase in medical aid membership of the 25-34 years old category has been only marginal and indeed many of these people are forced to be on medical aids due to compulsory membership rules from their employers.

Managed healthcare has come to the fore around the world during the past decade. It is broadly the practice of evidence based medicine and is used as an approach in managing both the quality and cost of medical care. What it essentially aims to do is to create systems that put controls in place so that the outcomes of medical care can be predicted with more certainty. It is thus a deliberate attempt by financiers to counteract the effects of cost-unconscious demands, which occurs whenever there is a third party payment system (Reekie, 1995: 80).

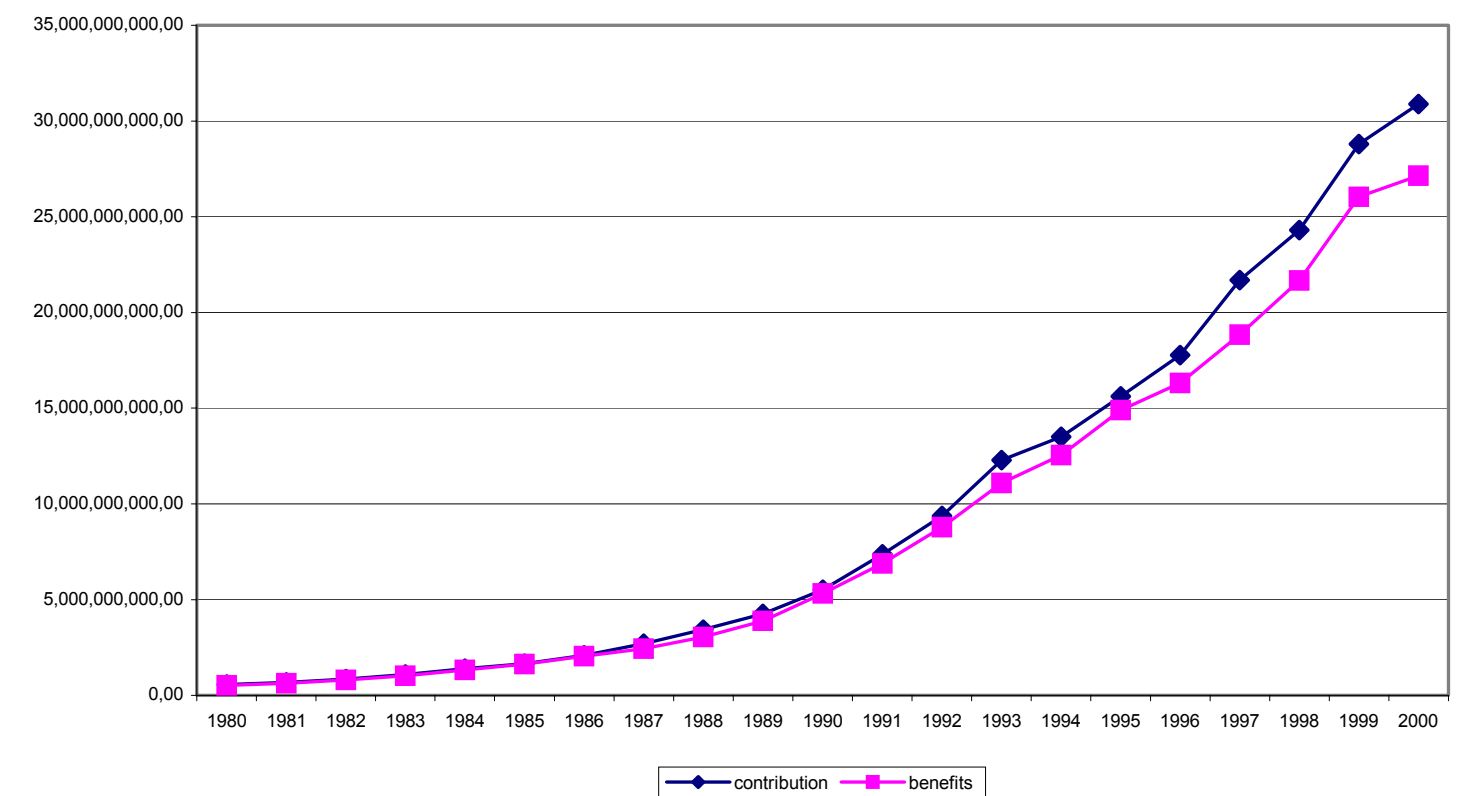

Figure 4: Contributions versus benefits

Source: Council for Medical Schemes (www.medicalschemes.com).

With rising pressure on medical aids to reduce costs various options have become available. The medical aids could try to control costs in its totality by forming their own healthcare organizations and vertically integrate by owning doctor practices, pharmacies and hospitals. Whilst this may give them full control, past experience has proved that companies do not perform well in areas that are not their core competencies. Another perhaps less drastic means would be to contract those services out to other companies under agreed terms. Below is a discussion of the various forms that managed healthcare has taken on and gives an indication of what managed healthcare will look like in the future. An example would be the forming of Health Maintenance Organisations (HMO) or Preferred Provider Organisations (PPO).

\section{Health maintenance prganisations:}

An HMO is a combination of a health insurer and health care delivery system. HMO's are responsible for providing healthcare services to members that is of a good quality and is appropriate. This form of health insurance has been especially successful in the USA. HMO's integrate the insurance function and the delivery of healthcare into a single organization. Staff based HMO's are those where providers are employed on a salary basis to provide services. Scheme members must then receive their consultations, medicines and hospital usage from HMO facilities or face a financial penalty. HMO's vary in structure with some embracing only hospital, others only general practitioners, while others embrace the whole health team (Reekie, 1995: 80).

With the development of new technology, providers and insurers can be linked by sophisticated systems which allow for constant cost monitoring. These systems can also prescribe recommended treatment regimens with providers having to justify using expensive procedures where not indicated or where cheaper methods are available. Reekie (1995: 81) reports that while $96 \%$ of all employer provided health insurance was traditional fee for service in 1984, by 1988 this has fallen to $28 \%$ in the USA. On the other hand, in South Africa fee for service is still the dominant means of private health care. One needs to ask why managed 
healthcare has not been more readily adopted in South Africa? The reason may be that companies traditionally offered only selected staff medical benefits and they could therefore afford to spend more for these select members of staff. Thus employers were not faced with the financial pressure of offering all staff medical aid subsidies.

There are signs that medical aids are beginning to bring about changes that will lead to the development of managed healthcare to its full extent in South Africa. An example of how healthcare can be brought to lower income people is Prime Cure. Prime Cure is a primary care provider that has built up a network of 50 medical centres around the country to deliver quality low-cost healthcare. The group provides patients with access to general practitioners, nurses and specialist services such as radiology and pathology and still manages to turn a decent profit. Prime Cure contracts with a further 250 service providers around the country, expanding its reach beyond the 50 centres. To achieve this Prime Cure had to redesign the way healthcare is delivered. They have done this by creating clinical protocols to ensure their doctors are fully up to date with the latest treatments and research. These protocols are integrated into an IT system that doctors can access in real time. This ensures that doctors generally get it right the first time without having to try many different treatments and running up medical bills. Prime Cure clinics are streamlined in such a way that the support-staff do the bulk of the work allowing doctors to see 90 or more patients per day (about double the industry norm). Prime Cure is paid a fixed fee per patient, eliminating incentives to over-service (Low cost quality pays off, 2002: 6). This is the type of healthcare service that the government would like to see proliferate as it will bring private health care within reach of a much larger number of people and will reduce the pressure on the public healthcare sector that does not have the resources to cope with the current demand.

\section{Preferred Provider Organization (PPO)}

This is an organization where health care services for members are purchased from select suppliers that have been contracted to supply the service. These providers follow agreed procedures and offer their services at lower negotiated rates. Members are encouraged to use participating providers by penalizing them with higher coinsurance if non-participating providers are used. They generally also include quality and utilization reviews. Providers who did not perform adequately in a given contractual period in terms of either price or quality could be de-listed from the PPO at contractual renewal (Chetty, 2000: 19).

\section{Goals of successful managed healthcare}

Traditionally managed care has focused on cutting costs and limiting the choice to those providers that are contracted into the system. This system has caused patients much aggravation as they feel a loss of control over their health. The new thinking is that managed care should entail more than just controlling costs and this has led to what is now called managed health. With managed health the customer becomes the focal point and is given much more freedom and decision-making power. The aim of managed health is for the patient to become informed and actively involved in their own health and well being.

The reason for this shift is that research shows that a very large percentage of healthcare costs are the result of unhealthy lifestyles. In the USA it is estimated that $\$ 188$ billion of annual healthcare costs can be attributed to unhealthy lifestyle costs and that one third of all deaths in the USA are due to unhealthy lifestyles involving tobacco, alcohol, poor diet and inactivity (Schaich, 1998: 23-30). The table below indicates how healthcare is likely to change from the more traditional managed care to the newer managed health systems.

\section{Table 1: Managed health versus managed care}

\begin{tabular}{|c|c|}
\hline Managed health & Managed Care \\
\hline $\begin{array}{l}\text { Focus on overall health status } \\
\text { managed health risk and } \\
\text { quality of health }\end{array}$ & $\begin{array}{l}\text { Focus on healthcare delivery } \\
\text { measuring healthcare costs and } \\
\text { delivery }\end{array}$ \\
\hline $\begin{array}{l}\text { Primary focus on consumers to } \\
\text { drive cost effective health, and } \\
\text { healthcare, choices }\end{array}$ & $\begin{array}{l}\text { Primary focus on providers to } \\
\text { drive cost-effective healthcare } \\
\text { choices }\end{array}$ \\
\hline $\begin{array}{l}\text { Providing access to multiple } \\
\text { health resources }\end{array}$ & $\begin{array}{l}\text { Limiting access to healthcare } \\
\text { resources }\end{array}$ \\
\hline $\begin{array}{l}\text { Proactive identification of } \\
\text { health risks and opportunities }\end{array}$ & $\begin{array}{l}\text { Active only after the need or } \\
\text { request for healthcare is present }\end{array}$ \\
\hline
\end{tabular}

Source: Schaich, 1998: 25.

The new thinking is that true managed health involves the consumer becoming part of the system and being educated as to how to live a healthier lifestyle. It also gives the consumer the freedom to make use of the best means of achieving this goal. For active participation to occur the population needs to have a general high level of education and sophistication. South Africa will need many years of sustained development to reach this point.

\section{The role of information technology (IT) in the healthcare market}

Many of the proposed solutions to healthcare challenges are only possible due to the rapid strides in IT development over the last few years. The advent of real time claims allows medical aids to know immediately what their liabilities are and allows the provider to know what benefits will be covered and what they will be willing to pay. This has dramatically reduced the administration costs and has had a very positive impact on service providers' cash flow, which at one stage had to wait up to sixty days for payment. The medical aids realize that the new technology has made fast payment possible and are now demanding larger discounts from providers. IT will probably play an even more important role in the future in the monitoring of the quality of the service provided. Ultimately medical aids hope this will lead to the standardization of treatment with the best quality and cost effective methods being used. New IT technologies will also make it possible for medical aids to 
introduce capitation plans which means that both providers and funders will share the risks.

\section{Recent reforms in healthcare in South Africa}

\section{Social health insurance}

When the ANC first came into power its health policy called for the development of a National Health Insurance with all members of the population contributing and receiving equitable healthcare (see Luiz, 1994). In the mid 1990's National Health Insurance was replaced by a new concept called Social Health Insurance (SHI). SHI restricts healthcare benefits to families of contributors alone. The reason for this shift was a recognition that the size of the formally employed market in South Africa is too small to subsidize the rest of the population. The SHI would thus focus on providing health care to low and middle-income workers and their families. This would be provided by public hospitals that would create special wards and offer amenities to SHI funded patients (Doherty, McIntryre \& Gilbon, 2000). SHI is distinguished from other forms of healthcare funding by the following features (Doherty et al., 2000):

- It is legislated by government and requires regular, compulsory contributions by members.

- Eligible members cannot opt-out of the scheme or be excluded by the scheme.

- Premiums are calculated according to ability to pay.

- Benefit packages are standardized.

- Contributions are earmarked for spending on health services.

The government is also the largest employer in the country and wants to provide healthcare to all its employees. Currently, due to the high cost of private healthcare, a large percentage of government workers have elected not to accept the government subsidy and join a medical aid. The government has already indicated that it intends to merge all the various government medical aids into one large medical aid to give it greater bargaining power. Initially the government indicated that it would tender to medical aid administrators to administer this new consolidated medical aid but it now seems unclear and it may administer the medical aid itself. The SHI would be an ideal means whereby government could bring its entire workforce under healthcare cover. By bringing more members under compulsory medical cover the burden of providing healthcare to these patients would be lifted, thus allowing the state to use tax-funded healthcare to improve provision to the very poor.

\section{Medical aid legislation}

Medical aids have had to contend with the new Medical Schemes Act of 1998 and the accompanying regulations of 1999 which were implemented in January 2000. The Act made it compulsory for medical aids to accept all eligible applicants and to charge contributions that were only differentiated on the basis of income and number of dependants and not on age or risk of ill health (Doherty \& McLeod, 2002: 2). The Act's intention was to widen private sector membership by outlawing discrimination. Medical aids could no longer only select patients that are considered good risks. Many believed this would be devastating to the medical aid industry. The feeling was that the young and fit would be forced to heavily subsidize the old and ill. This would cause them to desert medical aids, which would leave medical aids with no option but to pass on their spiralling medical costs to a dwindling pool of aged members. The elderly, unable to afford these rising costs, would be forced into using the poor state care and one private scheme after another would disappear. Fortunately the result has not been as dramatic as first envisaged. Whilst premiums initially increased at a much higher rate than previously, these increases were not at the hyper-inflationary level that many predicted. One reason may be that as medical aid costs have increased many people began buying down to cheaper, more affordable options that may not be as comprehensive. Nevertheless, the new regulations may have played a role in the rise in medical aid inflation in 2000 and 2001 and made it increasingly unattractive for younger members to join.

From January 2004 new legislation will force medical aids to cover a set of Prescribed Minimum Benefit conditions (PMB) that have been listed in the amended Medical Scheme Act 131 of 1998 . This legislation forces medical aids to cover these PMB's without the possibility of patients exceeding their benefits. Medical aids are allowed to introduce formularies to limit their financial exposure. Annexure A of the Act states that the objectives for this new legislation are twofold. First, to avoid incidents where individuals lose their medical cover in the event of serious illness and the consequent risk of unfunded utilisation of public hospitals. Second, to encourage improved efficiency in the allocation of private and public health care resources. While it is understandable for the government to want to limit its exposure to the risk of having to provide care for medical aid patients that have exceeded their medical aid limits, a risk exists that interfering in the economics of the private sector could lead to prices increasing dramatically and more people not being able to afford private healthcare.

\section{Risk equalization}

The government is concerned with open medical aids that will market their products to attract young and healthy patients to reduce their risk to the exclusion of needier patients - so-called cherry picking. This practice is often used as a justification for government intervention in the private medical aid market. One way the government wants to deal with this is to create a risk equalization fund into which all medical aids will be required to deposit a certain percentage of contributions received. Those funds with a higher risk profile will thus be able to claim from this fund to cover the costs of its older high-risk members. Ultimately government wants to force medical aids to charge the same premium for all members regardless of age and health risk and thereby force medical aids to compete on service. The government also wants to reform private medical aids to allow it to enforce mandatory cover for all employees. This 
will then force younger healthy individuals onto medical aids and thereby allow the young and healthy to subsidise the old and sick.

\section{Pharmacy legislation}

In 2003 the pharmacy legislation restricting pharmacy ownership to pharmacists was repealed, which now allows non-registered pharmacists to have equity in pharmacies. This has led to a long established pharmacy cartel in the country being broken. Government reports have long held the view that South Africa has too many outlets with too small a turnover to produce a profit (Reekie, 1997). This oversupply of outlets also adds other costs in the medicine price structure in that wholesalers must deliver small volumes of medicine to many outlets at considerable cost. The new legislation will allow large organisations with large capital and efficient distribution systems to enter the market. Increased competition will in time drive costs down.

\section{Generic substitution}

While South Africa has been slow in moving towards greater generic substitution this practice is gathering pace. This can be attributed to two factors. Firstly, the Pharmacy Act was changed allowing pharmacists to substitute the original with a generic without getting the doctor's approval. Secondly, the medical aids have introduced maximum medical aid prices that will only reimburse at the generic price requiring the patient to reimburse the difference. The move towards generics in South Africa brings us into line with other developing and emerging economies and will result in significant cost reductions.

\section{Medicine price control legislation}

In January 2004 a new proposed pricing structure was introduced for discussion for implementation in May 2004.
This new pricing structures replaces the current mark-up system with a professional fee. The aim is to remove the profit incentive from medicines. The proposed Act also requires pharmaceutical companies to charge $50 \%$ of their current list price to wholesalers and distributors. This proposed legislation has been met with fierce resistance. Many of the international companies complain that they do not discount and bonus as heavily as the new proposals imply and that should the proposals be accepted they will no longer be profitable. This has led to huge uncertainty in the market with retailers believing their businesses will not be sustainable at these levels of profitability and rumours abounding that some of the multinationals are considering exiting the country. While it is admirable for the Minister to reduce medicine prices, care should be taken to ensure that new models replacing the current system should be economically viable. Should the private sector falter as a result, healthcare in South Africa would worsen dramatically and not lead to improved healthcare which was the government's original intention.

\section{Future directions of health plans in South Africa}

Predicting the exact direction that the health plans will move in South Africa is not easy because so many factors are at play, but we do know that the private healthcare market will be moving towards reducing costs. Examining the international trend gives us some insight into the likely trajectory. Since the private sector has to date operated with limited government control and generally on free market principles much like the American private healthcare, the table below illustrates the direction the American healthcare market has followed in recent years. Assuming that the government sees the private healthcare market as a viable and important aspect of healthcare provision in South Africa the private sector may follow a similar trajectory.

Table 2: The evolution of health plans models

\begin{tabular}{|c|c|c|c|c|}
\hline & Indemnity & $\begin{array}{l}\text { Managed Indemnity } \\
\text { and PPO's }\end{array}$ & $\begin{array}{l}\text { Traditional } \\
\text { HMO's }\end{array}$ & $\begin{array}{c}\text { The next } \\
\text { generation: } \\
\text { managed health }\end{array}$ \\
\hline $\begin{array}{ll}\text { Healthcare cost } \\
\text { controls } \\
\text { Driving forces }\end{array}$ & $\begin{array}{l}\text { Focus on claims } \\
\text { Payer driven }\end{array}$ & $\begin{array}{l}\text { Focus on net- } \\
\text { work/plan design } \\
\text { Network/plan driven }\end{array}$ & $\begin{array}{l}\text { Focus on health } \\
\text { care access }\end{array}$ & $\begin{array}{l}\text { Focus on health } \\
\text { Consumer driven }\end{array}$ \\
\hline Program features & $\begin{array}{l}\text { Fee for service } \\
\text { Retrospective } \\
\text { claim review }\end{array}$ & $\begin{array}{l}\text { In/out of net-work } \\
\text { benefit } \\
\text { Pre-certification and } \\
\text { utilization review } \\
\text { Narrow panels }\end{array}$ & $\begin{array}{l}\text { Gatekeepers } \\
\text { Referrals and } \\
\text { authorizations } \\
\text { Capitation } \\
\begin{array}{l}\text { Provider } \\
\text { sharing }\end{array} \\
\text { Narrow panels }\end{array}$ & $\begin{array}{l}\text { Consumer and } \\
\text { provider education } \\
\text { Disease and demand } \\
\text { management } \\
\text { Self-care } \\
\text { wellness focus and } \\
\text { Open networks } \\
\text { Less hassle and more } \\
\text { choice }\end{array}$ \\
\hline
\end{tabular}


South Africa still falls predominately in the indemnity plan category but there has been a move recently towards the formation of Preferred Provider Organizations (PPO). There are groups which could soon form HMO's in South Africa. An obvious example is the Medicross group. Medicross has opened large doctors' practices across South Africa which includes dispensaries, dentists and radiography. Netcare, which owns the Medicross group, is one of the largest hospital owners in South Africa. This provides them with the opportunity to establish an HMO, with their vertical integration allowing them to control costs from the doctor to the hospital.

South Africa is thus potentially not that far from following the USA in its development of private healthcare. The USA has made many mistakes in its development of managed healthcare and South Africa has the advantage of being able to learn from them and only apply their best practices while taking cognisance of the local environment. The South African medical aids face an economic environment where there is a very wide distortion between incomes in the population and will thus have to develop products that are viable and meet the needs of different groups. In addition they will need to work with government which is showing a willingness to form public-private partnerships to bring better standards of healthcare to a larger proportion of people in South Africa.

\section{Evaluation and conclusion}

Health care in South Africa needs to undergo major changes if the government is to meet its goals of improving healthcare to the masses. How best to achieve its goals is a matter of much controversy. The government has resorted to a set of legislation (which many consider draconian) which restricts free markets and tries to regulate increased access. It is not clear that these regulations will in fact result in this objective. For example, a ruling by the Competition Tribunal in May 2003 takes issue with government's intention to issue certificates of need to force doctors and pharmacists into rural areas. The Tribunal argued that the best way to reduce high profit margins is in fact to lower entry barriers and increase competition. Wealthy, urban areas, which the government considers over-serviced, will see profit margins decline if more entry occurs and the market itself will result in the relative profit margins between urban and rural areas declining. By restricting new entrants into the urban markets the result will be even higher profits in these areas. The Tribunal urged the Department of Health to in fact ease entry to the market and allow competitive principles to govern.

The Department of Health has adopted a reactionary set of policies which will 'punish' the private sector, minimise their profits and restrict competitive and market forces. These policies may well undermine the private sector to such an extent that it becomes unviable. The Pharmacy Council has recently stated the new laws regarding pricing of medicines will result in $80 \%$ of pharmacies becoming unviable. If this is true, then the result will not be to lesson the burden on the state but in fact to increase it. The message from the Competition Tribunal should be heeded that what South African healthcare needs is increased competition as that will be the most effective way to reduce medical inflation. Medical aids are already forcing doctors and pharmacies to substitute with generics where possible. We are seeing movements towards managed healthcare which should lower costs as well. Further pressure on medical aids themselves (which have been raising their premiums in excess of the inflation rates) will come if we see increased competition in that market. However, the trend in this regard has been in the opposite direction: three decades ago there were roughly double the number of medical schemes with half the beneficiaries (Doherty \& McLeod, 2002: 2). This coincides with rising administration fees charged by medical schemes - it more than doubled between 1997 and 2001 (in constant 2001 prices) (Doherty \& McLeod, 2002: 8). We need to increase competition in this market by making it more attractive not less so. The rising tide of health legislation is making the health market less appealing and will see further drops in medical scheme numbers.

Not all the blame should be laid on the government. It has adopted this coercive legislation because of its frustration with the lack of increased access to private medical care. The private sector has not been pro-active enough in coming up with innovative options to service the lower income market. Instead we have medical schemes competing with each other for the same stagnating pie. Medical schemes have resorted to competing not by expanding access or lowering prices but by adopting all sorts of 'bells and whistles' with little medical rationale e.g. cheap movie tickets.

South African healthcare is at a crossroads. If the current legislation is introduced as it stands it will severely undermine free markets and the private sector. But likewise South Africa cannot continue with the current practices which are not servicing the masses. A common ground needs to be found whereby private and public health systems find synergies that will allow larger numbers of people to fall under the medical aid insurance net. This will allow public healthcare to focus its resources on the unemployed and very poor. Should there not be a mutual agreement South African healthcare could regress and this will lead to huge costs in the future.

\section{References}

Chetty, M. 2000. Introduction to the basics of managed care in South Africa. Durban: Parke-Davis.

Council For Medical Schemes. 2002. [online] URL www medicalschemes.com.

Doherty, J., McIntryre, D. \& Gilson, L. 2000. 'Social health insurance.' In South African Health Review 2000. Durban: Health Systems Trust.

Doherty, J. \& McLeod, H. 2002. 'Medical schemes.' In South African Health Review 2002. Durban: Health Systems Trust. 
Filmer, D. et al. 2002. 'Weak links in the chain II: A prescription for health policy in poor countries.' The World Bank Research Observer, 17(1): 45-68.

Havemann, R. \& Van der Berg, S. 2003. 'The demand for healthcare in South Africa'. Journal for Studies in Economics and Econometrics, 27(3): 1-27.

'Low cost quality pays off.' 2002. Sunday Times. $16^{\text {th }}$ June 2002: 6.

Luiz, J.M. 1994. 'Health care in the new South Africa: Surveying the more radical options', Africa Insight, 24(2): 127-132.

Reekie, W.D. 1995. Health-care options for South Africa: Lessons from the UK and the USA. Sandton: Free Market Foundation.

Reekie, W.D. 1997. 'Cartels, spontaneous price discrimination and international pharmacy retailing', International Journal of the Economics of Business, 4(3): 279-285.

Rietveld, A.H. 1996. 'Assessing the opportunities for managed healthcare in the Netherlands'. Paper presented at the IIR Limited Conference in London, 28-29 February.

Financial Mail, 26 July 2002:50. 'Running out of patients'.

Ryan, C. 2002. 'Pharmaceuticals and health-care: A Finance Week Special Report', Finance Week, 28 August: 1-22.

SAIRR. (South African Institute of Race Relations). 2001. South Africa Survey 2001/2002. Johannesburg: SAIRR.

Schaich, R.L. 1998. 'Managed health: The new frontier in healthcare delivery', Managed Healthcare, Jan: 23-30.

UNDP. 2001. Human Development Report 2001. New York: United Nations. 